\title{
Avaliação de Erosão por Imagens de Aeronave Remotamente Pilotada a Baixa Altura de Voo
}

\author{
Evaluation of Erosion by Short-Distance Images obtained by Remotely Piloted \\ Aircraft
}

\section{Evaluación de Erosión por Imágenes a Corta Distancia obtenidas por Aeronave Remotamente Pilotada}

\author{
Alexandre Aquino da Cunha ${ }^{1}$ \\ Mauro José Alixandrini $\mathrm{Jr}^{2}$ \\ Vivian de Oliveira Fernandes ${ }^{3}$
}

\begin{abstract}
RESUMO: Este artigo tem como objetivo a proposição de um estudo acerca da avaliação do potencial do Aeronave Remotamente Pilotada, também conhecida como RPA (Remotely Piloted Aircraft), como plataforma de obtenção de dados para monitoramento de erosão. É proposta uma metodologia para monitorar processos erosivos oriundos de ravinas e voçorocas, com geração de ortofoto e modelo digital de elevação, proporcionando condições de se executar medidas precisas de parâmetros de comprimento, área e volume para quantificação do processo erosivo. Na primeira área de estudo foram aplicados testes em uma região de morro para cálculo de volume positivo, no qual foram utilizados pontos de apoio e sinalização de marcações no solo. Com isso, o valor do volume obtido com o uso de RPA obteve valores finais próximos dos valores de referência com a utilização da estação total. Assim, pode-se dizer que a utilização de marcações no solo foi uma técnica que favoreceu melhores resultados nos testes propostos. No levantamento com o RPA na segunda região de estudo verificou-se a diminuição da densidade na nuvem de pontos devido à oclusão de algumas áreas interiores da ravina, ocasionando altas discrepâncias de volume nas comparações com os valores de referência.
\end{abstract}

PALAVRAS-CHAVE: Aerofotogrametria. RPA. Erosão.

ABSTRACT: This paper aims a study about evaluation of the Remotely Piloted Aircraft (RPA) potential, as a platform to obtain data for erosion monitoring. A methodology was proposed to monitor erosive processes from ravines and gullies, with orthophoto generation and a digital elevation model, providing conditions to execute precise measurements of length, area and volume parameters for

\footnotetext{
1 Núcleo de Operações Técnicas da Coordenação de Desenvolvimento Agrário do Estado da Bahia (CDABA). Av. Luiz Vianna Filho, Conjunto Seplan, CAB - 41745-000 - Salvador - Bahia. aquinoc@ufba.br. 2 Escola Politécnica da Universidade Federal da Bahia. Rua Prof. Aristides Novis no 02 Federação, CEP: 40210-630. Salvador - Bahia. mauro.alixandrini@ufba.br.

${ }^{3}$ Escola Politécnica da Universidade Federal da Bahia. Rua Prof. Aristides Novis no 02 Federação, CEP: 40210-630. Salvador - Bahia.vivian.deofernandes@gmail.com.
} 
quantification of the erosive process. In the first study area, tests were applied in a hill region, to calculate positive volume, as well as points of support and signaling marks on the soil. That being said, the value of the volume obtained with the use of RPA obtained final values close to reference values obtained through measurement with total station. Thus, it can be said that the use of markings in the soil for correlation of images, was a technique that favored better results. In the survey with RPA in the second study region arranged in a ravine area, for calculation of negative volume, it was observed that there was a decrease in the density of the cloud of points due to occlusion of some interior areas of the ravine, causing high volume discrepancies in comparisons with the reference values.

KEYWORDS: Aerophotogrammetry. RPA. Erosion.

RESUMEN: Este proyecto de investigación tiene como objetivo la proposición de un estudio sobre la evaluación del Aeronave Remotamente Pilotada, también conocida como RPA (Remotely Piloted Aircraft), como plataforma en la obtención de datos para monitoreo de la erosión. Los métodos empleados en estudio de artículo se mostraron prometedores para monitoreo de erosión y fortalece el uso del RPA como plataforma de medición. La primera área de estudio se aplicaron pruebas en una región de morro, para cálculo de volumen positivo, y se utilizaron puntos de apoyo y señalización de marcas en suelo. Con ello el valor de volumen obtenido con el uso de RPA obtuvo valores finales próximos a los valores de referencia, con uso de estación total. Así, se puede decir que la utilización de marcas en el suelo, fue una técnica que favoreció para mejores resultados. En el levantamiento con el RPA en la segunda región de estudio, donde se aplicó pruebas en un área de ravina se observó que ocurrió una disminución de densidad en la nube de puntos debido a la oclusión de algunas áreas interiores de ravina, ocasionando altas discrepancias de volumen en las comparaciones con los valores de referencia.

PALABRAS-CLAVE: Aerofotogrametría. RPA. Erosión.

\section{INTRODUÇÃO}

A erosão superficial do solo representa um significativo problema ambiental. O estudo do fenômeno exige medições precisas da superfície do solo. A erosão, entendida como um processo de degradação do solo devido à atuação dos fatores naturais e antrópicos, tem cada vez mais merecido a atenção dos pesquisadores. A fotogrametria digital é proposta neste trabalho como uma técnica útil para tais medições. Os recursos tecnológicos disponíveis à cartografia têm viabilizado avanços consideravelmente importantes, principalmente através dos softwares e equipamentos que permitem velocidade na obtenção de dados, na troca de informações espaciais e em sofisticadas análises dos fenômenos espaciais (SANTOS; SEGANTINE, 2006). Paralelamente, o avanço tecnológico no que diz respeito às câmeras aéreas e aos sistemas de navegação, em conjunto com a necessidade de redução de tempo e custos nos processos de mapeamento, fez surgir novos sistemas de aquisição de imagens aéreas, que é o caso do veículo aéreo não tripulado. Portanto, o intuito deste trabalho é fazer uso do VANT, do tipo remotamente pilotado (RPA), através de imagens à baixa altura de voo, como uma nova ferramenta de mapeamento do uso do solo, verificando-se a viabilidade e qualidade de suas informações no monitoramento de 
processos erosivos. A principal hipótese levantada é que a caracterização de processos erosivos a partir de imagens ortorretificadas e modelos digitais de elevação gerados por aeronaves remotamente pilotadas possuem melhor eficiência que métodos convencionais de topografia e sensoriamento remoto orbital, uma vez que permite que os resultados sejam obtidos com menor custo e de forma mais rápida, viabilizando melhor manuseio dos dados. Além disso, o fácil manuseio do equipamento VANT em levantamentos de campo permite com que determinadas falhas nas imagens obtidas sejam corrigidas de forma rápida, através de novas idas a campo.

Essa pesquisa irá definir e delimitar quais processos erosivos podem ser monitorados por imagens, verificando a aplicabilidade do sensoriamento remoto por imagens à baixa altura de voo para auxílio na avaliação e monitoramento de impactos ambientais causados por erosão. Para isso, será realizada a parametrização de técnicas de levantamento com RPA mais adequadas para viabilizar a aplicação e análise da evolução de processos erosivos.

O objetivo principal é elaborar uma metodologia para avaliar processos erosivos e obter parâmetros que caracterizem a erosão, como volume, área, comprimento das diferentes estruturas (cauda, corpo e cabeceira), classes de interesse no entorno (vegetação, uso do solo, corpos d'água e edificações), baseadas em imagens à baixa altura de voo, utilizando a plataforma RPA e fotogrametria terrestre para obtenção de dados. O uso do RPA como plataforma de obtenção de dados para estudos no monitoramento de erosão baseia-se no seu baixo custo e na possibilidade de acoplamento de câmeras com resoluções propícias a gerar produtos com excelente acurácia.

A aplicação servirá como base para pesquisas posteriores e aplicável a situações semelhantes em qualquer região, e será de fundamental importância para o desenvolvimento dos estudos futuros. Os dados serão disponibilizados de forma digital, e de fácil manipulação. Entre as principais aplicações pode-se citar a geração de mapas e de outras informações para suporte aos PRADs (Planos de Recuperação de Áreas Degradadas).

\section{MAPEAMENTO COM RPA}

O termo VANT é o mais utilizado para classificar os Veículos Aéreos Não Tripulados ou UAV (Unmanned Aerial Vehicle), ou seja, que tenham autonomia de voo sem piloto, também chamados de RPA (Remotely-Piloted Aircraft) ou RPAS (Remotely-Piloted Aircraft System). A possibilidade de aquisição de imagens por esses equipamentos tem se difundido nos últimos anos. 
O imageamento com RPA tem algumas características distintas da fotogrametria aerotransportada tradicional seja pelo uso de câmeras não métricas sejam pelos algoritmos empregados no processamento dos dados gerados. As sobreposições longitudinais e laterais são bem superiores; em geral os valores mínimos empregados são 80\% e 60\% respectivamente, em um bloco fotogramétrico; isso porquê essa sobreposição é necessária para criar gradientes que indicam a direção do movimento relativo dos alvos na detecção automática de pontos. As seguintes práticas foram adotadas na aquisição: sensor com resolução de 12 megapixels, velocidade de disparo superior a 1/1000, balanço de branco, e monitorou-se a quantidade de luz solar e a nebulosidade para que se tenha condição homogênea durante o recobrimento. São importantes para um recobrimento mais eficiente monitorar condições de vento e tempestades eletromagnéticas. Um último fator diz respeito à altitude e ao padrão imageado; caso não existam feições no terreno suficientes para uma distribuição homogênea de pontos identificados automaticamente é indicado o uso de marcas pré-sinalizadas a fim de criar artificialmente detalhes pela área a ser imageada.

\section{Pontos de Controle}

Existem RPAS que possuem em seu sistema embarcado um receptor GNSS (Global Navigation Satellite System) de navegação, que é responsável por executar a missão programada em escritório e gravar a posição onde cada imagem foi tomada. Porém a precisão de um receptor GNSS de navegação fica em torno de 5 a 10 metros; isso significa que um ponto coletado por este receptor, quando verificado no terreno, pode estar em um raio de 5 a 10 metros. Dessa forma, precisa-se utilizar pontos de controle com o objetivo de aumentar a acurácia do mapeamento. Os pontos de controle utilizados neste trabalho constaram em alvos distribuídos ao longo do cenário experimental. Por se tratarem de feições bem definidas na imagem e no terreno, ou seja, cujas coordenadas são conhecidas, estes podem ser extraídos por meio de levantamento em campo por topografia, de acordo com a resolução espacial da imagem a ser corrigida (SILVA, 2000).

Destaca-se que pontos de controle são pontos cujas coordenadas são, preferencialmente, determinadas em campo através de métodos de posicionamento; na atualidade são utilizados métodos de posicionamento GNSS que garantam qualidade compatível com os objetivos propostos do voo. Por exemplo, o posicionamento relativo rápido estático permite atingir a qualidade de centímetros na determinação de coordenadas em campo (GALVÃO; ROSALEN, 2013). Para os pontos de controle, além dos pontos présinalizados, podem ser escolhidos detalhes que estariam visíveis tanto na imagem como no terreno, como, por exemplo, o canto de uma faixa de estacionamento, o canto de uma esquina, enfim intersecções visíveis. Com isso, o projeto ganha uma velocidade maior em 
sua execução, já que é possível iniciar a coleta dos pontos de controle com grande antecedência ao voo ou até após a execução do voo, pois estes alvos naturais, de antemão, não serão removidos do solo.

Com os valores das coordenadas dos pontos de controle, é utilizado o software de pós-processamento para encontrar os alvos nas imagens e introduzir as coordenadas dos alvos coletadas em campo com receptor GNSS. O software utiliza estas coordenadas como referência em sua aerotriangulação; com isso, ele transporta estas coordenadas para o restante dos pixels na imagem fazendo assim o processo de georreferenciar a imagem. Dessa forma, cada pixel terá sua coordenada estabelecida, diante do processo de aerotriangulação (ALIXANDRINI JUNIOR et al., 2016).

Com a finalidade de apoiar o processamento e o aumento da precisão das imagens, alguns estudos têm sido desenvolvidos utilizando pontos de controle no apoio ao aerogeorreferenciamento e correção geométrica das imagens de RPA (GALVÃO; ROSALEN, 2013).

\section{Modelo Digital do Terreno}

Os modelos em perspectiva são conhecidos como Modelos Digitais do Terreno (Digital Terrain Model ou DTM), ou Modelos Digitais da Superfície (Digital Ground Model, DGM). Para criação do Modelo Digital do Terreno (MDT) tem-se como primeira etapa a seleção e a filtragem das fotografias. A seleção é realizada manualmente, antes das fotografias serem adicionadas à ferramenta computacional, excluindo aquelas que apresentaram problemas de qualidade decorrentes da inclinação da aeronave no momento da tomada da fotografia (fotografias obliquas); da variação da altitude do RPA entre tomadas consecutivas (variação de escala); e da deriva da mesma provocada pelo vento (arrasto). No processamento seguem-se as etapas de alinhamento das tomadas, otimização do alinhamento, construção de uma nuvem densa de pontos, construção de um modelo poligonal de interpolação (poligonal mesh mode/), edição da geometria, construção de modelo digital de elevação, texturização e ortomosaico (DIGITAL GLOBE, 2013).

No alinhamento das tomadas são detectados pontos homólogos entre as regiões de sobreposição das imagens criando uma nuvem esparsa de pontos e estimada a posição de cada tomada do recobrimento da área. Os parâmetros utilizados nesse estágio são: grau de acurácia na definição dos pontos homólogos, modo de seleção de pares (para os casos de se ter ou não posições aproximadas nas tomadas) e quantidade limite de pontos candidatos (ou chave) e de ligação de faixas. O limite de pontos candidatos indica quão fina será a varredura na imagem para busca de pontos individualizados que serão utilizados como candidatos para pontos homólogos nos modelos e entre faixas do bloco de recobrimento. 
A construção da nuvem densa de pontos é a etapa de densificação dos pontos fotogramétricos onde são refinados os parâmetros de posição da câmera no instante da tomada de cada imagem e são calculados a partir da nuvem esparsa de pontos. Nessa etapa pode-se lançar mão da identificação de pontos de apoio com coordenadas conhecidas; eles auxiliam o refinamento do georreferenciamento do bloco de recobrimento. São parâmetros do algoritmo: a definição fina ou grosseira da nuvem e o filtro de profundidade que faz menção a capacidade de identificação de padrões mais complexos intra texturizados (MIKHAIL; BETHEL; MCGLONE, 2001). No que diz respeito à geração de um MDT a partir de um estereomodelo orientado, de acordo com Schenk (1996), é necessário realizar três etapas, descritas da seguinte forma:

1. Correspondência de imagens: esta etapa consiste em localizar pontos homólogos, sendo denominada também de correlação de imagens, uma vez que permite encontrar pontos homólogos em pares de imagens;

2. Ajuste da superfície: diz respeito à interpolação de pontos para que a superfície seja representada de forma correta;

3. Controle de qualidade: caracteriza-se por ser a verificação e edição do MDT. Esta etapa é de fundamental importância, pois os MDT's gerados de forma automática ainda necessitam de edição.

A formação do modelo poligonal de interpolação diz respeito à operação que constrói a geometria da superfície baseada na construção de faces a partir dos pontos da nuvem densa. Esse modelo pode ser editado excluindo faces criadas equivocadamente e preenchendo buracos derivados da oclusão de detalhes ou da retirada de obstáculos.

O Modelo Digital de Elevação pode ser criado do modelo poligonal de interpolação ou diretamente da nuvem densa de pontos para exportação. Ele também pode ser texturizado com base no imageamento original ou no ortomosaico derivado da ortoretificação do recobrimento do bloco.

\section{Erosão}

No intuito de compreender melhor os agentes que caracterizam os fenômenos relacionados à erosão, torna-se necessário apresentar conceitos que caracterizem o que vem a ser um solo e as suas principais características. Dessa forma, de acordo com Lima e Lima (2007), o solo é definido como um corpo natural que cresce de forma demorada, não se reproduz e morre com facilidade. Então, é necessário que o mesmo seja protegido e que sejam conhecidos os elementos da natureza que fazem parte da sua formação. 
Bertoni e Lombardi Neto (1990) afirmam que o solo é resultado de uma ação integrada e simultânea do clima e de organismos (geralmente rocha), que ocupa determinada localidade ou relevo, durante um determinado período de tempo. Durante seu desenvolvimento o mesmo sofre a ação de diversos processos de formação relacionados às perdas, transformações, transportes e adições, sendo estes responsáveis pela transformação da rocha em solo, diferenciando-se desta por ser constituído de uma sucessão vertical de camadas que diferem entre si na cor, espessura, granulometria, conteúdo de matéria orgânica e nutrientes de plantas.

A erosão, entendida como um processo de degradação do solo devido à atuação dos fatores naturais e antrópicos, tem, cada vez mais, merecido a atenção dos pesquisadores, tanto no que diz respeito à manutenção da produtividade agrícola como no que se refere à preservação de uma forma geral.

\section{DESENVOLVIMENTO}

\section{Área de Estudo}

A área de estudo está situada na Universidade Federal da Bahia (UFBA), que é uma instituição de ensino superior pública brasileira, com sede na cidade de Salvador. Compreende duas regiões distintas, onde os voos foram realizados. A região 1 está localizada na Praça das Artes, região central do Campus de Ondina, conforme visto na figura 1a. A região de estudo 2 (figura 1b) está localizada no Centro Esportivo da UFBA, mais especificamente no bairro de Ondina, quadra de esportes, na Escola de Educação Física da referida instituição. Tais regiões ficam na área que compreende a Poligonal UFBA, região de aproximadamente 79.000 metros.

Figura 1 - a) Vista da região 1 de estudo - b) Vista da região de estudo 2

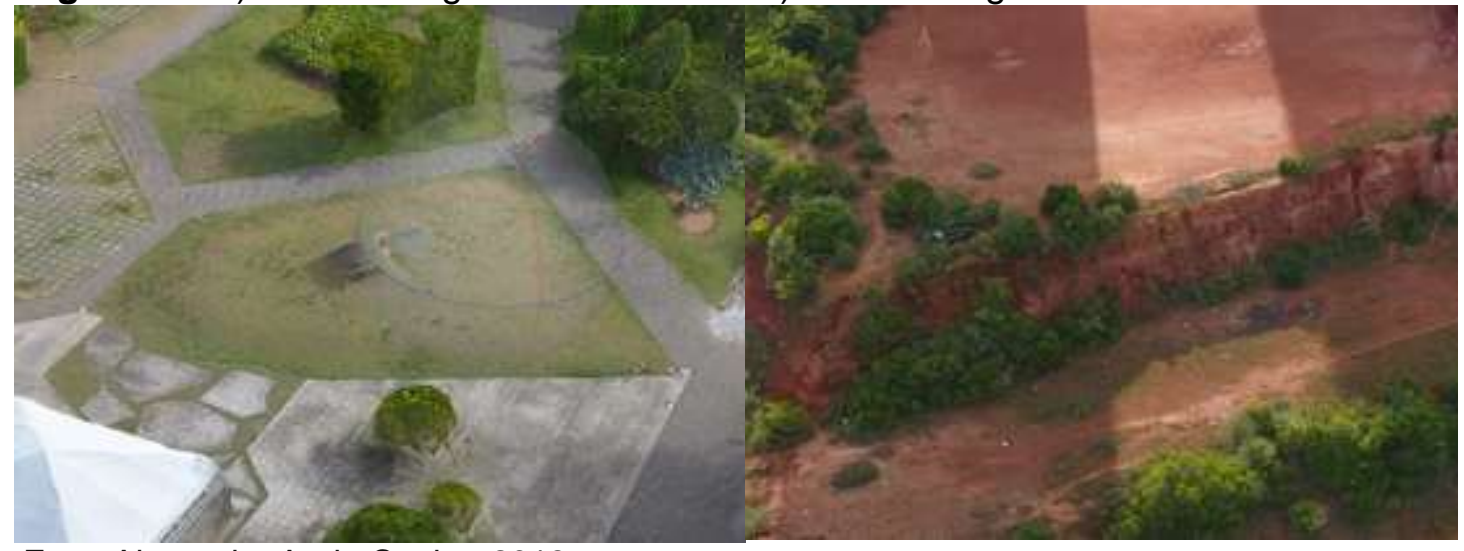

Foto: Alexandre A. da Cunha, 2018. 


\section{Materiais}

Neste estudo foram utilizados softwares e equipamentos do Laboratório de Fotogrametria e Sensoriamento Remoto do Departamento de Engenharia de Transportes e Geodésia (UFBA), aos quais também são pertencentes as licenças dos softwares:

a) RPA DJI phantom 4 de asa rotativa: utilizado para obtenção das imagens da área;

b) Estação Total Ruide RTS 862A;

c) Receptores GNSS Ashtech ProMark 120, portadora L1, com bipé, bastão e uma trena;

d) Software Topcon Tools v.7.5.1: software de pós-processamento onde foi executado o transporte de coordenadas dos pontos de controle;

e) Software Pix4D para realização do plano de voo;

f) Software Agisoft PhotoScan 1.2.4: para processamento de imagens provenientes do drone para gerar o modelo tridimensional (3D);

g) Software DataGeosis: para processamento dos dados provenientes da Estação Total;

h) Software ArcGis para modelagem dos dados provenientes dos voos na quadra de esportes da UFBA;

i) Software Qgis para criação de mapas.

\section{Método}

Foi utilizado o método experimental, pois as variáveis foram manipuladas de maneira preestabelecida e seus efeitos suficientemente controlados. Foi realizado um aprofundamento do referencial teórico relacionado ao tema, e assim desenvolvido uma metodologia de campo (plano de voo, avaliação de perímetro e pontos de controle) para obter resultados satisfatórios. O estudo de caso foi realizado em regiões de áreas pequenas, para que possíveis ajustes na metodologia fossem feitos. Após essa etapa, foram realizados voos na área de estudo. A metodologia atual foi adaptada a partir dos resultados anteriores de campo, para obter melhores resultados. A metodologia empregada para a execução deste trabalho encontra-se descrita no fluxograma da figura 2. No estudo preliminar foram realizadas visitas de reconhecimento para identificação de obstáculos, obstruções e local adequado para decolagem.

Os valores obtidos em campo permitem com que sejam avaliadas as discrepâncias dos resultados volumétricos entre diferentes tecnologias, utilizando Modelagem Digital de Terreno (DTM) elaborado a partir de pesquisas utilizando RPA, e Estação Total como dados de referência em áreas de teste localizadas na região de estudo. 
Figura 2 - Fluxograma dos métodos empregados no presente trabalho

\begin{tabular}{|c|c|c|c|c|}
\hline $\begin{array}{l}\text { Avaliacăo do } \\
\text { Perimetro: } \\
\text { Riscos, } \\
\text { Obstáculos, } \\
\text { Recobrimento }\end{array}$ & $\begin{array}{c}\text { Plano de voo: } \\
\text { Autonomia, } \\
\text { visadas, } \\
\text { condiçóes } \\
\text { meteorológicas }\end{array}$ & $\begin{array}{l}\text { Aquisiçalo dos } \\
\text { dados e } \\
\text { imagens com } \\
\text { RPA }\end{array}$ & $\begin{array}{l}\text { Processamento } \\
\text { das fotografias }\end{array}$ & $\begin{array}{l}\text { Avaliaçäo dos } \\
\text { resuitados }\end{array}$ \\
\hline
\end{tabular}

Fonte: Elaborado pelos autores.

Foram realizadas comparações entre os volumes, áreas e análises estatísticas, obtidos através dos modelos gerados com RPA e estação total, conforme destacados no fluxograma da figura 3.

Figura 3 - Fluxograma sequenciando testes aplicados na execução dos voos

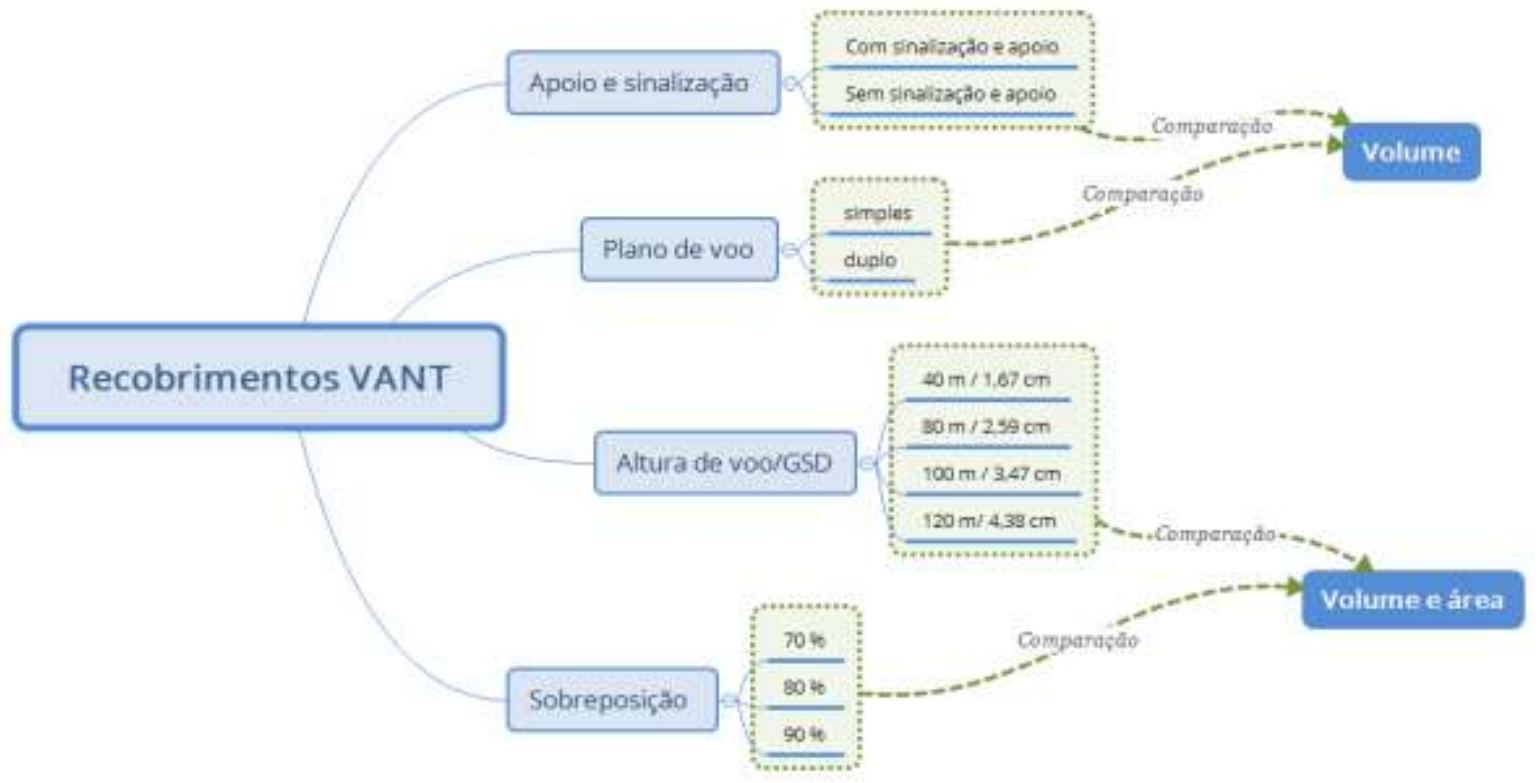

Fonte: Elaborado pelos autores.

O primeiro e o segundo teste, no fluxograma da figura 3, apoio/sinalização e plano de voo, foram realizados na região de estudo 1. Neles foram utilizados apoios (pontos de controle) e sinalizações utilizando fitas adesivas, formando linhas (figura 4) para possivelmente melhorar a correlação de imagens, através da melhor identificação de pontos homólogos. Também, nesses testes, foram utilizados dois tipos de planos de voo, o plano de aquisição de imagem de grade simples e o de grade dupla. Após os voos com o uso do RPA, as imagens foram processadas, gerando o Modelo Digital do Terreno e Ortofoto Digital, sendo possível extrair informações de medidas de volume e comprimento para comparações com dados de referência obtidos através da Estação Total. 
Figura 4 - llustração da região de estudo 1, com marcações de fita adesiva

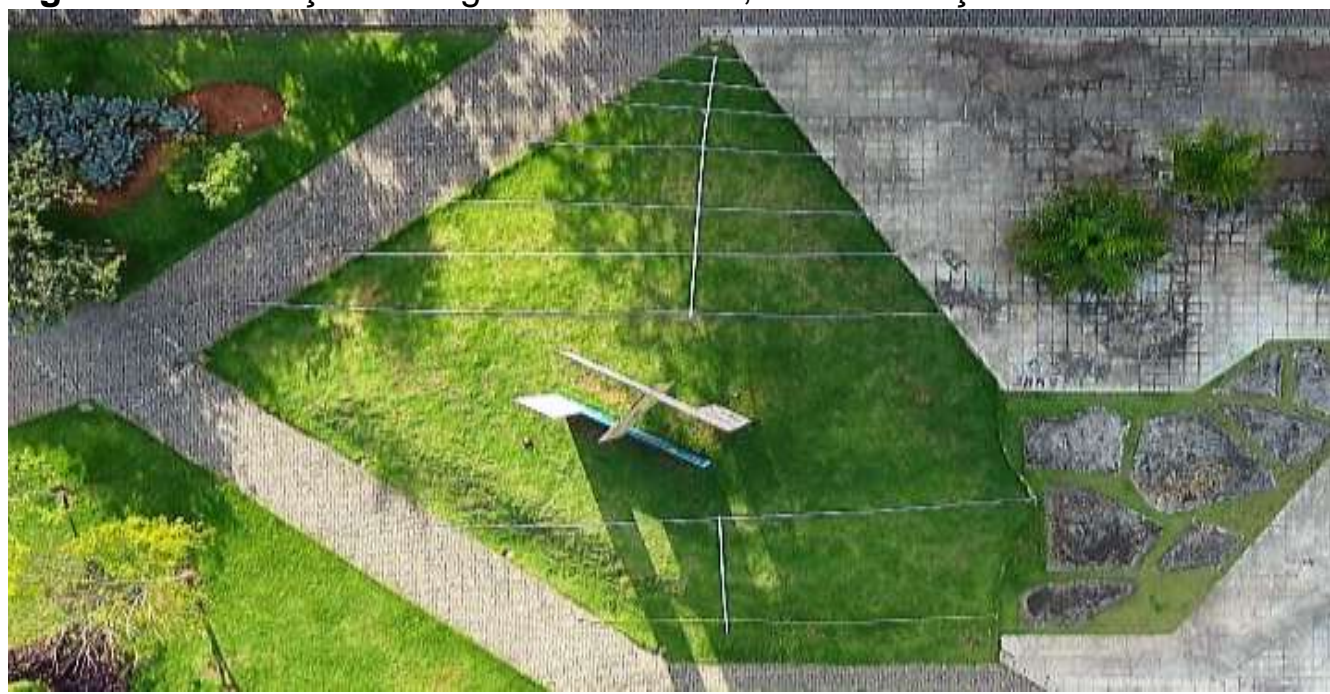

Foto: Alexandre A. da Cunha, 2018.

Na terceira comparação foram alterados os parâmetros da altura de voo, variando o GSD (Ground Sample Distance) da imagem gerada. Essa fase foi executada nas duas regiões de estudo, Praça das Artes e Centro Esportivo da UFBA (figura 5). Teve como objetivo comparações de volume e área entre os modelos obtidos com uso de RPA e Estação Total, bem como realização de testes estatísticos.

Figura 5 - Ortofoto georreferenciada da região de estudo 2 no Centro Esportivo com áreas MORRO 01 e MORRO 02

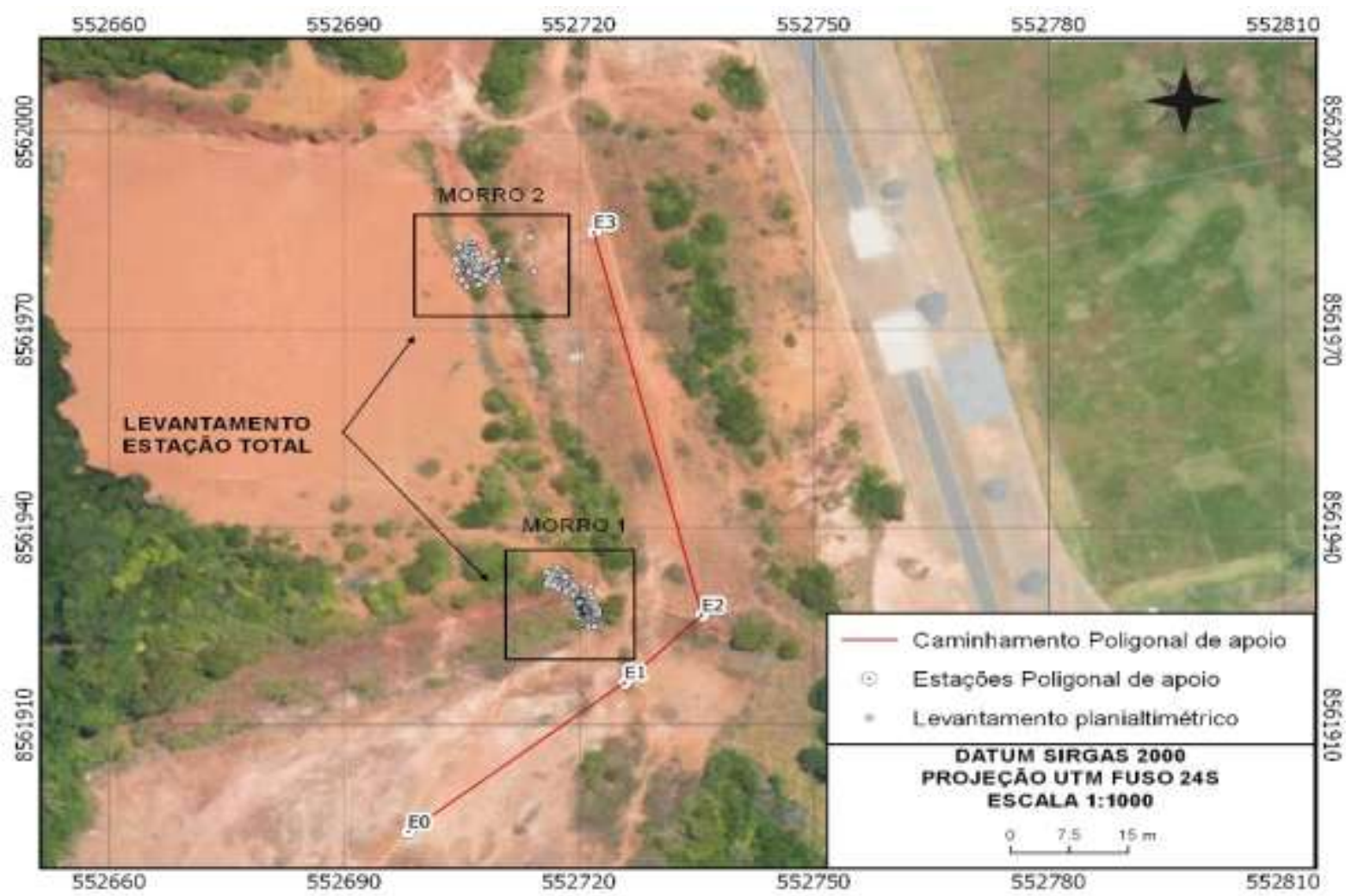

Fonte: Elaborado pelos autores. 
$\mathrm{Na}$ quarta comparação foi realizado na íntegra na região de estudo 2 (Praça das Artes), onde os parâmetros de sobreposição foram alterados, com objetivo de verificar se existe um padrão de variabilidade na diferença de volume e área entre os dados do VANT e Estação Total, bem como realização de testes estatísticos.

\section{RESULTADOS OBTIDOS}

\section{Região de Estudo 1}

Para efeito de comparação de dados, foram utilizados como valores de referência os dados obtidos através da Estação Total. É importante salientar que o tempo de coleta nessa etapa inclui o levantamento com receptor GNSS, utilizado para georreferenciar os pontos da poligonal. Foram levantados 160 pontos. O cálculo do volume foi executado no software DataGeosis, a partir da triangulação dos pontos da nuvem densa, que são ligados, de modo a construir uma malha de triângulos recorrendo a algoritmos de triangulação topográfica. Após a execução do cálculo de volume, chega-se ao valor de 189,99 metros cúbicos para a região 1 , que se caracteriza como uma região que fornecerá um volume positivo, por se tratar de um morro.

O cálculo do volume do produto gerado pelo RPA foi possível a partir da triangulação dos pontos da nuvem densa, que são ligados, de modo a construir uma malha de triângulos recorrendo a algoritmos de triangulação. Na região de estudo foram gerados aproximadamente 147 mil pontos por voo após a execução de voo variando tipo de grade, inclusão ou exclusão de sinalização e pontos de controle no solo.

Nesta região em estudo foram alterados os parâmetros da altura de voo, variando o GSD, acrônico no inglês Ground Sample Distance que significa: distância de amostra do solo. As alturas testadas foram 40 metros, 80 metros e 120 metros. Buscou-se, com isso, verificar a influência da diminuição da nuvem densa de pontos (quanto maior a altura, menor a quantidade de pontos na nuvem densa) em relação à variação do volume e área de superfície do modelo digital (vide quadro 1).

No quadro 2 foram calculados a média, variância e desvio padrão. Esses dois últimos, são medidas de dispersão que indicam a regularidade de um conjunto de dados em função da média aritmética. 
Avaliação de Erosão por Imagens de Aeronave Remotamente Pilotada a Baixa Altura de Voo

Quadro 1 - Variação percentual do cálculo do volume, realizadas com o RPA e Estação Total, com voo simples, a 40, 80 e 120 metros de altura e marcação e pontos de controle em solo

\begin{tabular}{|c|c|c|c|c|c|c|c|c|}
\hline \multicolumn{2}{|c|}{ MÉTODO } & $\begin{array}{l}\text { QUANTIDADE } \\
\text { DE PONTOS }\end{array}$ & $\underset{\left(m^{3}\right)}{\operatorname{VOLUME}}$ & $\begin{array}{c}\text { VARIACCÃO } \\
\text { PERCENTUAL }\end{array}$ & $\begin{array}{c}\text { ÁREA } \\
\left(\mathrm{m}^{2}\right)\end{array}$ & $\begin{array}{l}\text { VARIAÇÃO } \\
\text { PERCENTUAL }\end{array}$ & $\begin{array}{l}\text { TEMPO DE } \\
\text { COLETA }\end{array}$ & $\begin{array}{c}\text { TEMPO DE } \\
\text { PROCESSAMENTO }\end{array}$ \\
\hline \multicolumn{2}{|c|}{$\begin{array}{l}\text { ESTAÇÃO } \\
\text { TOTAL }\end{array}$} & 160 & 189,99 & & 328,96 & & 5 horas & 35 minutos \\
\hline \multirow{3}{*}{ RPA } & $40 m$ & 147000 & 183,21 & 0,04 & 337,30 & 0,03 & $\begin{array}{c}15 \\
\text { minutos }\end{array}$ & 35 minutos \\
\hline & $80 m$ & 100300 & 151,67 & 0,20 & 323,67 & 0,02 & 9 minutos & 22 minutos \\
\hline & $120 m$ & 52600 & 149,99 & 0,21 & 322,65 & 0,02 & 6 minutos & 12 minutos \\
\hline
\end{tabular}

Elaborado: pelos autores.

Quadro 2 - Análise estatística da discrepância da altimetria dos pontos homólogos do RPA e Estação Total, da região de estudo 1, Praça das Artes

\begin{tabular}{|c|c|c|c|c|c|c|c|c|}
\hline \multicolumn{3}{|c|}{ PRAÇA DAS ARTES VOO 40m } & \multicolumn{3}{|c|}{ PRAÇA DAS ARTES VO0 80m } & \multicolumn{3}{c|}{ PRAÇA DAS ARTES VOO 120m } \\
\hline MÉDIA & DEV PAD & VAR & MÉDIA & DEV PAD & VAR & MÉDIA & DEV PAD & VAR \\
\hline 0,01 & 0,28 & 0,08 & $-0,06$ & 0,28 & 0,08 & $-0,06$ & 0,29 & 0,08 \\
\hline
\end{tabular}

Elaborado: pelos autores.

\section{Região de Estudo 2}

Também nesta região, para efeito de comparação de dados, foram utilizados como valores de referência os dados obtidos através da Estação Total. A região foi dividida em dois grupos: MORRO 1 e MORRO 2, conforme visto na figura 5 anteriormente. É importante ressaltar que na região de estudo 2 o corpo de estudo serão duas ravinas, e serão avaliados os volumes negativos.

O tempo de coleta nessa etapa inclui o levantamento com receptor GNSS, utilizado para georreferenciar os pontos da poligonal. Foram levantados 204 pontos no MORRO 1 e 102 pontos no MORRO 2. O cálculo do volume foi executado no software ArcGIS, a partir da criação do Modelo Digital de Superfície TIN. 
No MORRO 1 foram alterados os parâmetros da altura de voo, variando o GSD (Ground Sample Distance) da imagem gerada. As alturas testadas foram 40, 60, 80 e 100 metros. Buscou-se, com isso, verificar a influência da diminuição da nuvem densa de pontos (quanto maior a altura, menor a quantidade de pontos na nuvem densa) em relação à variação do volume e área de superfície do modelo digital. O processamento de dados das análises de diferença de superfícies foi realizado através do software ArcGIS Desktop 10.5 com o suporte à extensão $3 D$ Analyst.

A análise de diferença de superfícies consistiu em calcular a área superficial e o volume do sólido, computado da interseção entre o terreno e uma superfície de referência. Para todos os cenários analisados, utilizou-se o fluxograma de geoprocessamento representado na figura 6 .

Figura 6 - Fluxograma de geoprocessamento para cálculo de área e volume

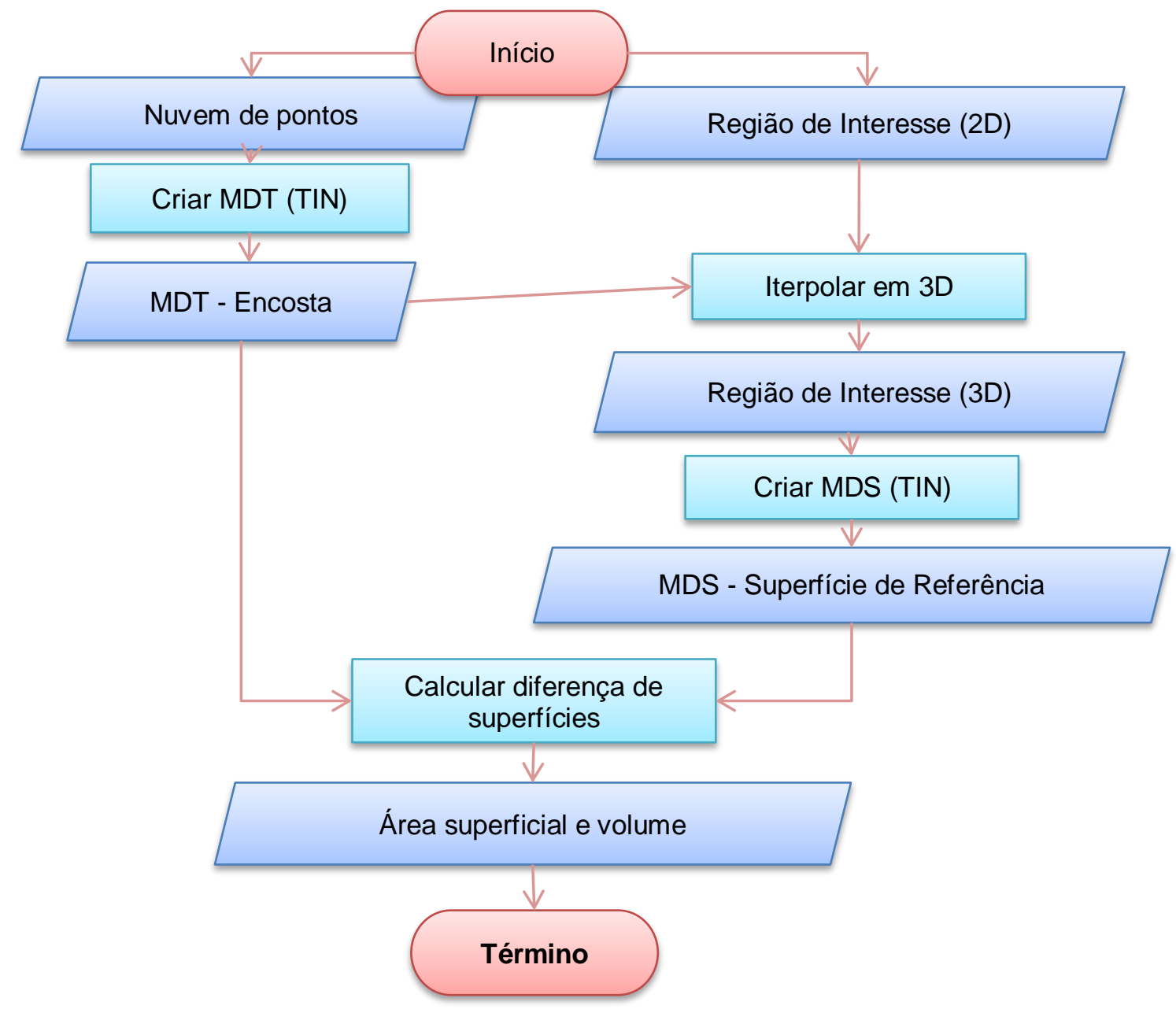

Fonte: Elaborado pelos autores. 
O processo tem como entrada o dado "nuvem de pontos", que representa a amostragem de pontos planialtimétricos do terreno e o dado "Região de interesse (2D)", polígono plano que delimita a região de interesse para a avaliação da área superficial e volume da ravina.

Inicialmente, criou-se o dado "MDT - Encosta", que consistiu no modelo digital de terreno da encosta oriundo da nuvem de pontos planialtimétricos amostrados. Este processo foi realizado utilizando a ferramenta Create TIN. Em seguida, processou-se o dado "Região de Interesse 3D", que consiste num polígono cujo valor da coordenada altimétrica de seus vértices tem como referência o modelo "MDT - Encosta". Este processo foi realizado utilizando a ferramenta "Interpolate shape 3D". Na sequência, processou-se o dado "MDS Superfície de Referência" que consistiu na criação do modelo digital da superfície de referência, oriundo da triangulação dos vértices 3D do dado "Região de Interesse 3D". Este processo foi realizado utilizando a ferramenta Create TIN. Por fim, através da ferramenta Surface Difference, foi realizada a diferença entre as superfícies "MDT - Encosta" e "MDS Superfície de Referência" cujo objetivo foi computar a área superficial e volume do sólido resultante da interseção entre esses dois modelos. A figura 7a representa o modelo gerado a partir dos pontos da estação total, que serão utilizados como referência do MORRO 1. A figura $7 \mathrm{~b}$ representa o modelo gerado a partir da estação total, que serão utilizados como referência do MORRO 2.

A figura 8 apresenta os modelos gerados a partir dos pontos provenientes do RPA, respectivamente nas alturas 40,60, 80 e 100 metros do MORRO 1. Nela é possível observar o aumento das diferenças acima do relevo de referência conforme o aumento da altura de voo. A figura 9 apresenta os modelos gerados a partir dos pontos provenientes do RPA, respectivamente nas sobreposições $70 \%$ e $80 \%$ do MORRO 2.

Os modelos apresentados na figura 10 referem-se à diferença de intensidade de pixel entre as representações matriciais de declividade gerados pela estação total e o RPA nas sete situações descritas anteriormente. O ponto de coloração mais escura significa maior diferença de pixel e, também, regiões problemáticas no levantamento com RPA que ocasionaram maior discrepância de volume, assim como se verifica na figura 11 onde a segunda área revela que o aumento da sobreposição pode interferir no comportamento dos modelos de elevação. 
Figura 7 - a) Análise da diferença de superfície do MORRO 1 - Estação Total b) Análise da diferença de superfície do MORRO 2 - Estação Total

a)
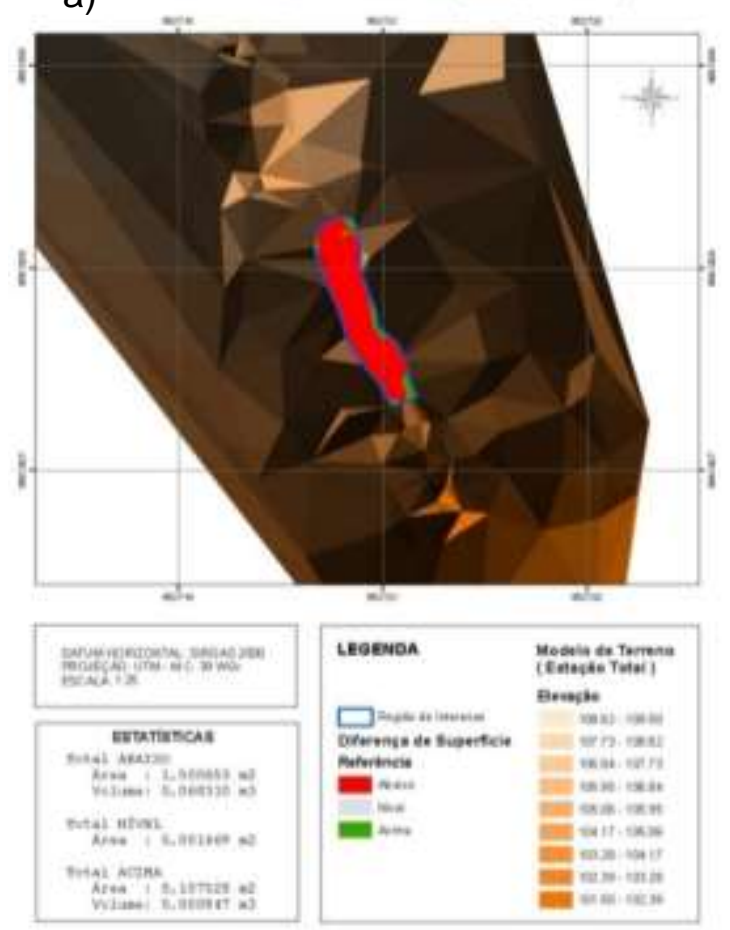

Fonte: Elaborado pelos autores. b)

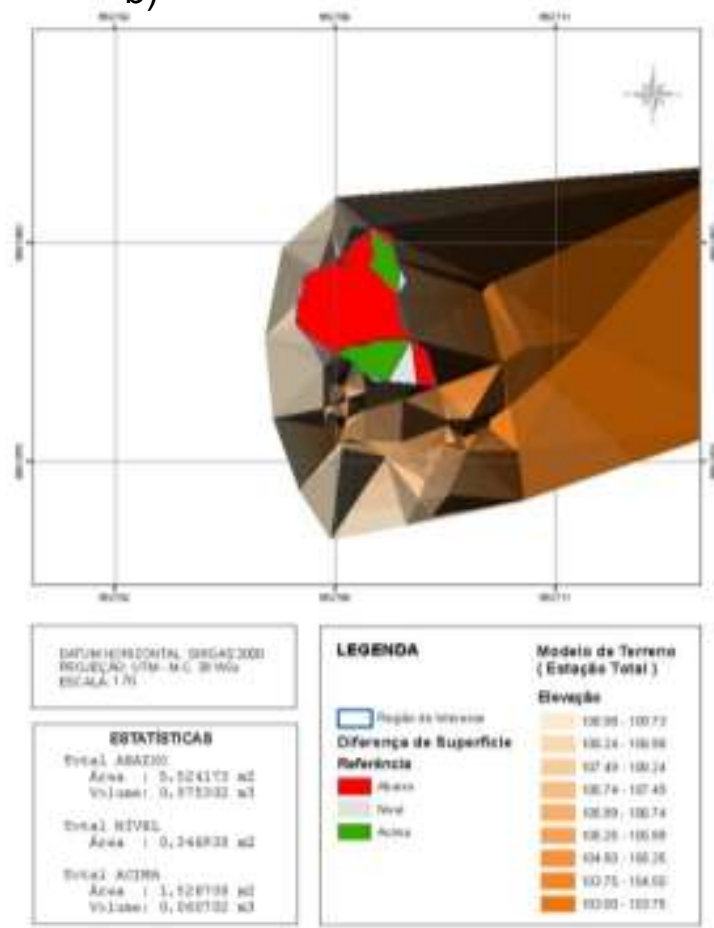


Figura 8 - Mapas com diferença de superfície para as alturas de 40, 60, 80 e 100 metros a) - Diferença de superfície - Altura 40m

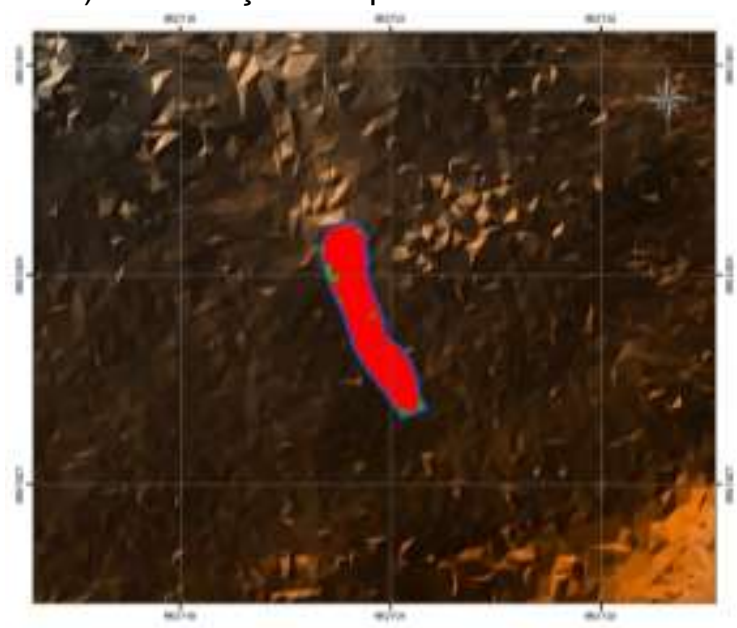

b) - Diferença de superfície - Altura $60 \mathrm{~m}$

c) Análise da diferença de superfície Altura $80 \mathrm{~m}$

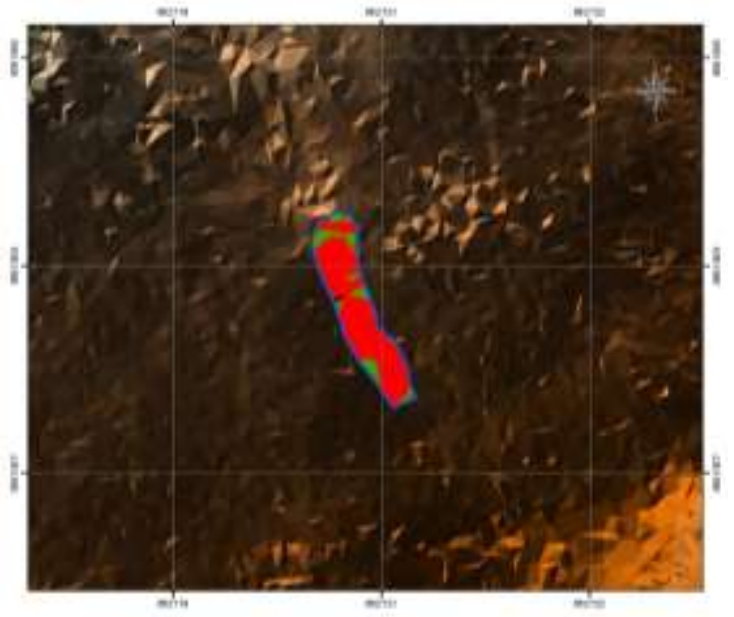

d) Análise da diferença de superfície Altura $100 \mathrm{~m}$
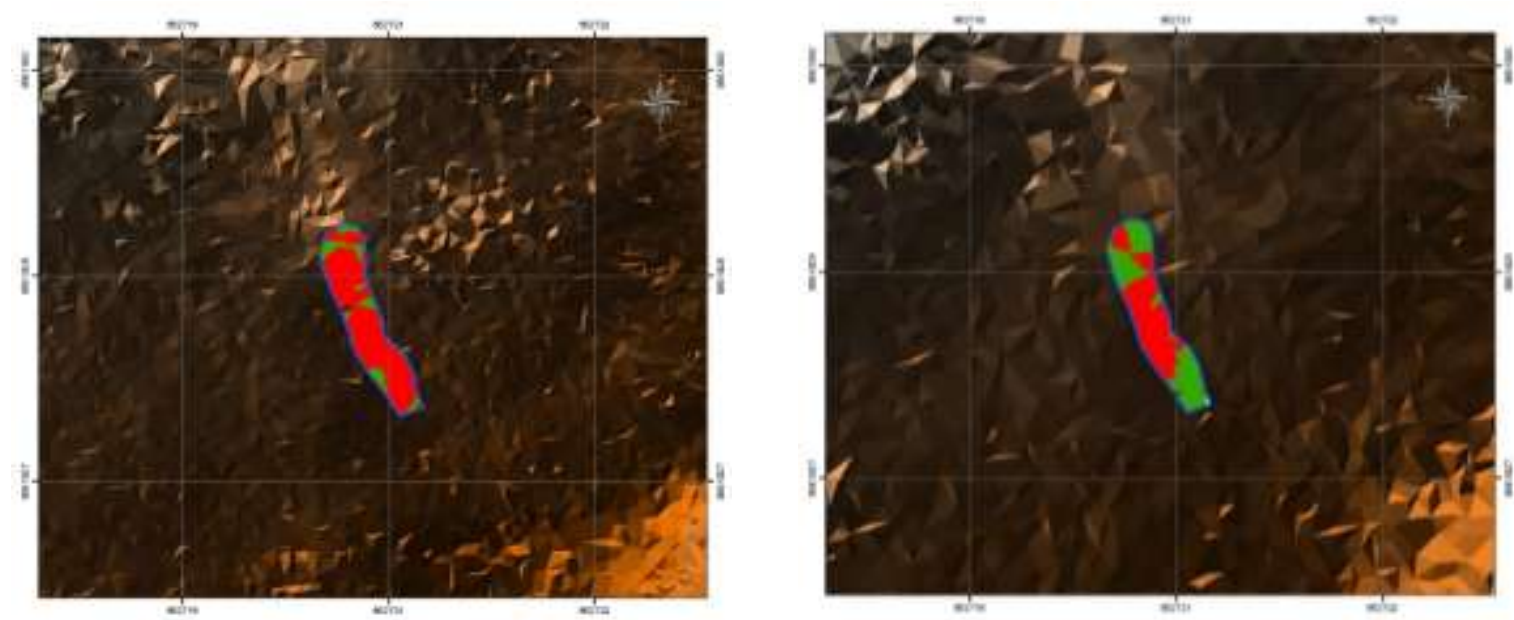

\section{LEGENDA}

Regiăo de interesse

Diferenga de Superficie Referēncia

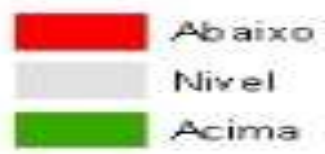

Modelo de Terreno (bloco_04_100m)

Elevação

\begin{tabular}{|c|}
$108.62-109.50$ \\
$107.73-108.62$ \\
$106.84-107.73$ \\
$105.95-106.84$ \\
$105.06-105.95$ \\
$104.17-105.06$ \\
$103.28-104.17$ \\
$102.39-103.28$ \\
$101.50-102.39$ \\
\hline
\end{tabular}

Fonte: Elaborado pelos autores. 
Figura 9 - Mapas com diferença de superfície para as sobreposições de $70 \%$ e $80 \%$

a) Análise da diferença de superfície -

Sobreposição de $70 \%$

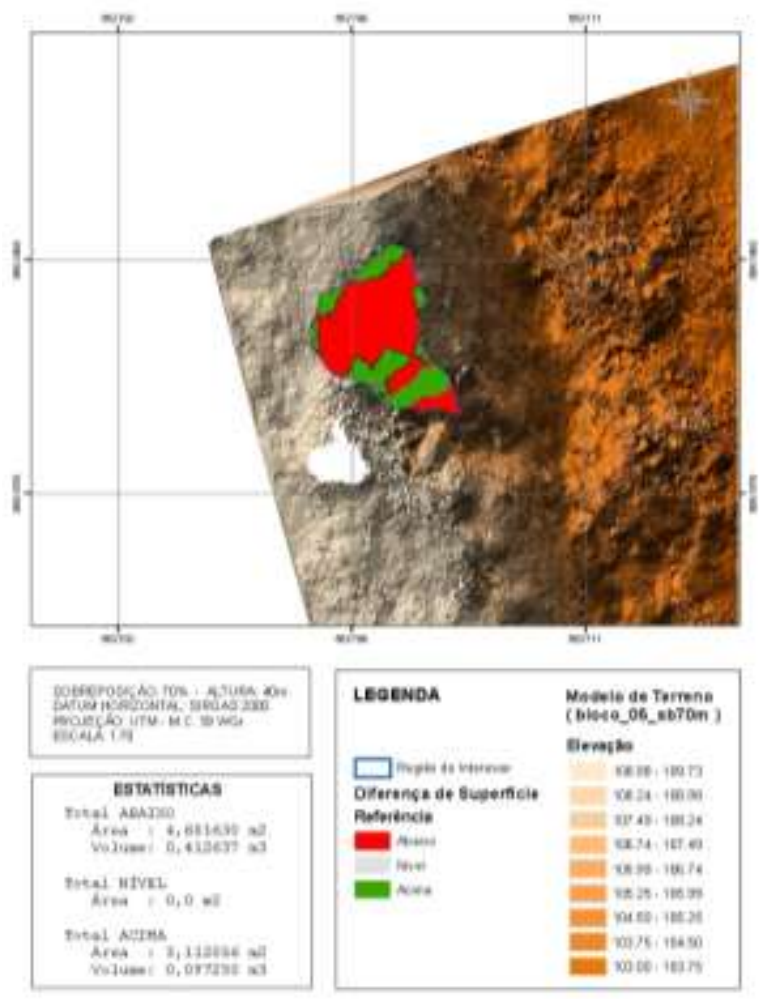

b) Análise da diferença de superfície Sobreposição de $80 \%$
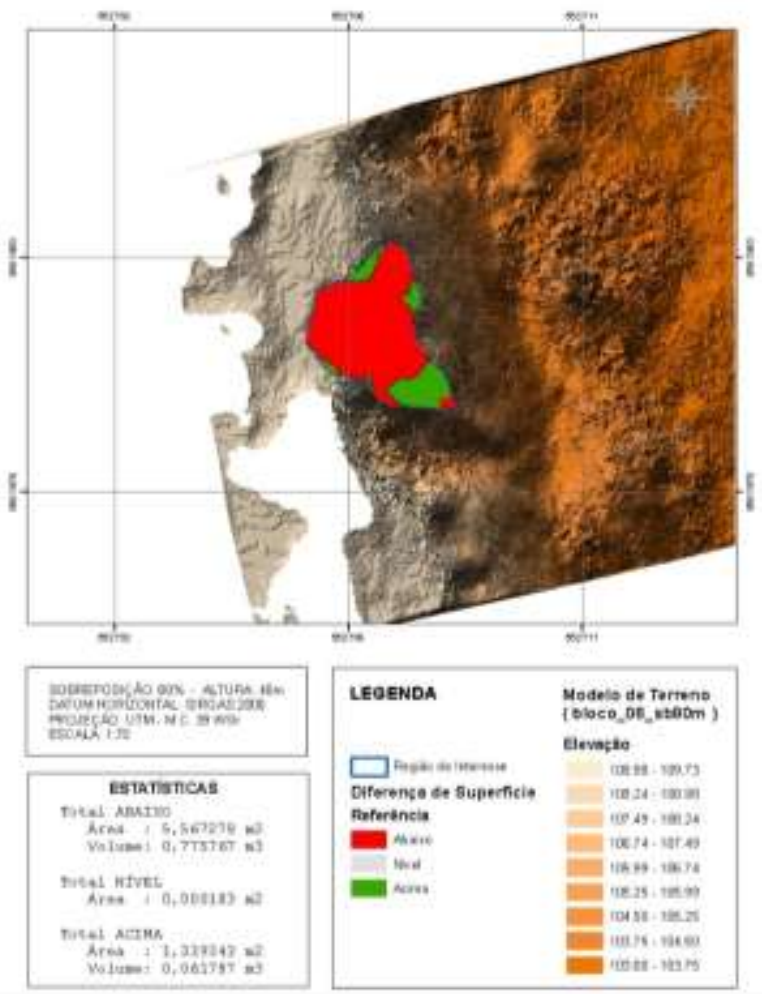

Fonte: Elaborado pelos autores.

Figura 10 - Diferença de intensidade de pixel entre as representações matriciais de declividade gerados pela estação total e o RPA com alturas de 60, 70, 80 e 90 metros
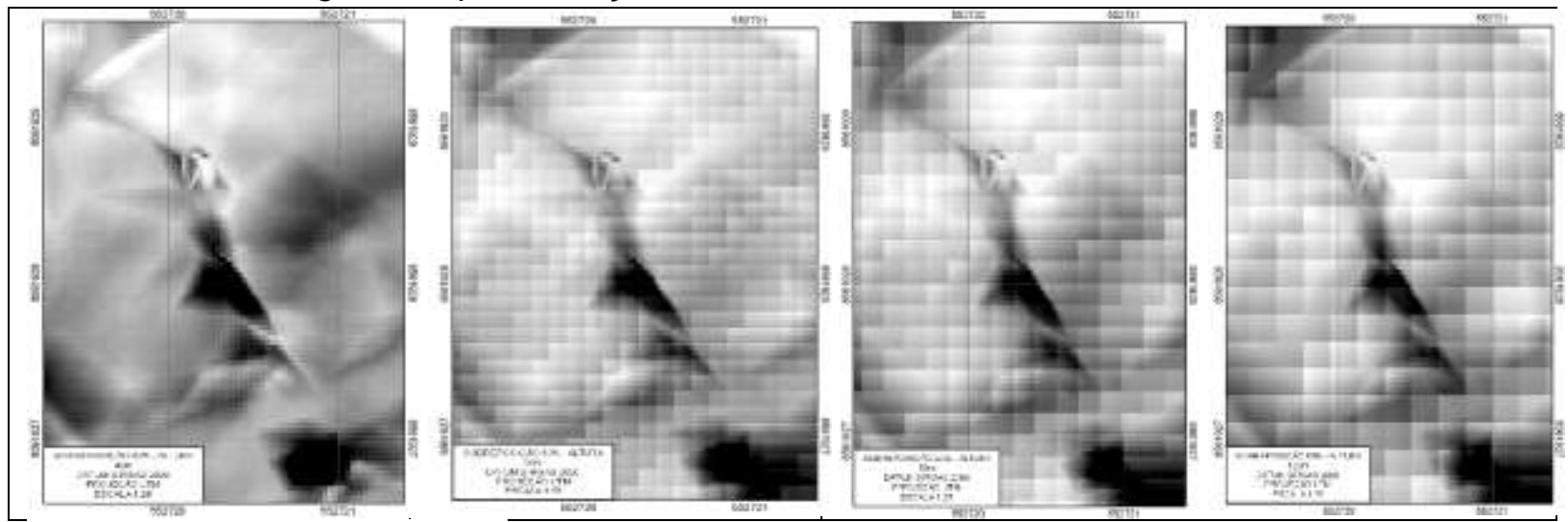

Fonte: Elaborado pelos autores. 
Figura 11 - Análise da diferença de intensidade de pixel - Sobreposição de 70\%, 80\%, 90\%
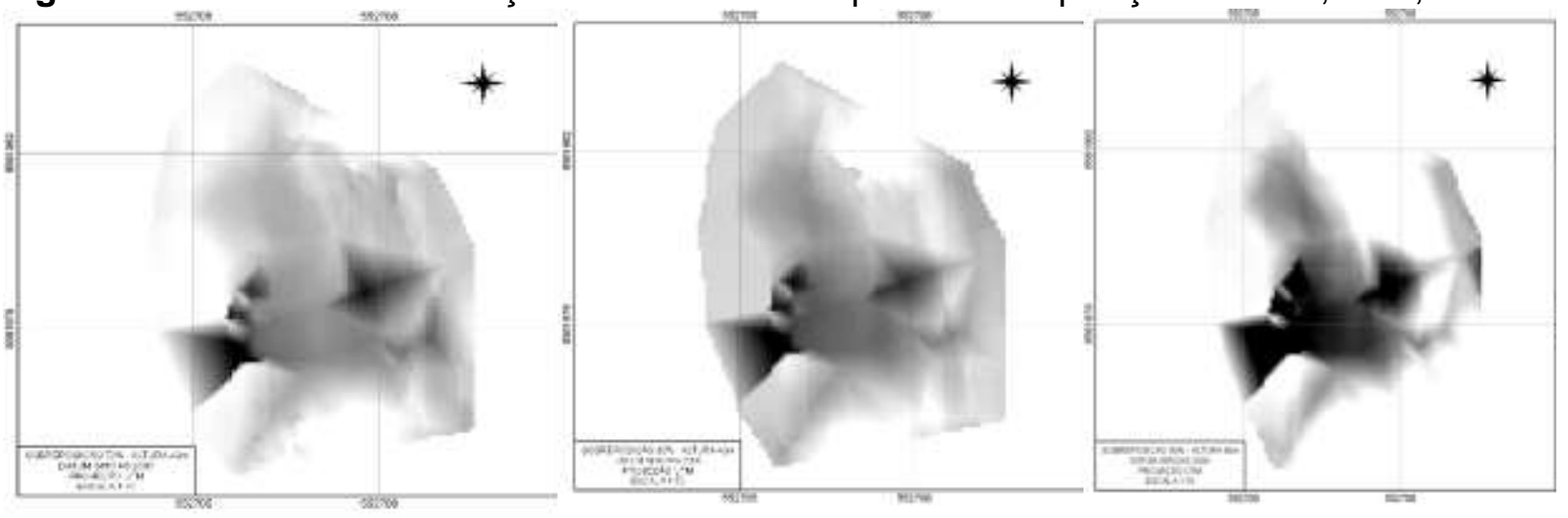

Fonte: Elaborado pelos autores.

No quadro 6 foram calculados a média, variância e desvio padrão da discrepância da altimetria dos pontos homólogos do RPA e Estação Total, da região de estudo 2, MORRO 1 e no quadro 7 a do MORRO 2.

Quadro 6 - Análise estatística da discrepância da altimetria dos pontos homólogos do RPA e Estação Total, da região de estudo 2, MORRO 1 em metros

\begin{tabular}{|c|c|c|c|c|c|c|c|c|}
\hline \multicolumn{3}{|c|}{ BLOCO 1 - 40m } & \multicolumn{3}{c|}{ BLOCO 3 - 80m } & \multicolumn{3}{c|}{ BLOCO 4 - 120m } \\
\hline MÉDIA & DEV PAD & VAR & MÉDIA & DEV PAD & VAR & MÉDIA & DEV PAD & VAR \\
\hline 0,04 & 0,23 & 0,05 & 0,06 & 0,29 & 0,08 & 0,09 & 0,3 & 0,09 \\
\hline
\end{tabular}

Elaborado: pelos autores.

Quadro 7 - Análise estatística da discrepância da altimetria dos pontos homólogos do RPA e Estação Total, da região de estudo 2, MORRO 2 em metros

\begin{tabular}{|c|c|c|c|c|c|c|c|c|}
\hline \multicolumn{3}{|c|}{ MORRO 2} & \multicolumn{3}{|c|}{ MORRO 2} & \multicolumn{3}{|c|}{ MORRO 2} \\
\hline \multicolumn{3}{|c|}{ BLOCO 5 - SB70 } & \multicolumn{3}{|c|}{ BLOCO 6 - SB80 } & \multicolumn{3}{|c|}{ BLOCO 7 - SB90 } \\
\hline MÉDIA & DEV PAD & VAR & MÉDIA & DEV PAD & VAR & MÉDIA & DEV PAD & VAR \\
\hline$-0,75$ & 1,08 & 1,17 & $\begin{array}{l}-0,64 \\
\end{array}$ & 1,01 & 1,02 & $\begin{array}{l}-0,72 \\
\end{array}$ & 1,04 & 1,08 \\
\hline
\end{tabular}

Elaborado: pelos autores.

\section{CONCLUSÕES}

Diante dos resultados apresentados no levantamento com o RPA, a partir de análises na região de estudo 1, sem a utilização de pontos de apoio e sinalização de marcação no solo o cálculo de volume utilizando a aerofotogrametria digital por RPA com câmera de pequeno formato é um produto com baixa precisão e confiabilidade para dados de altimetria, 
visto que suas comparações de discrepâncias com os dados levantados por estação total obteve um valor de $16,58 \%$.

Os resultados revelam que no levantamento com o RPA na região de estudo 1, utilização de pontos de apoio e sinalização de marcações no solo, os valores de discrepâncias na comparação com uso de estação total foram minimizados, e os volumes com grade simples e dupla se aproximaram do valor de referência, 1,87\% e 0,28\% respectivamente. Logo, a utilização de marcações no solo, para auxiliar na correlação de imagens foi uma técnica que favoreceu melhores resultados nos testes propostos para avaliar o potencial do RPAS.

Ainda na região de estudo 1 , com utilização de pontos de apoio os valores de discrepâncias na comparação com uso de estação total e RPA não variaram de forma significativa com o aumento da altura de voo, como vistos na comparação de volume, discrepâncias de 0,04\%, 0,20\% e 0,21\%, e na comparação de área de superfície, 0,03\%, 0,02\% e 0,02\%, respectivamente para as alturas 40, 80 e 120 metros.

No levantamento com o RPA na região de estudo 2, MORRO 1, a mudança de altura de voo (40, 60, 80 e 100 metros) não ocasionou uma mudança proporcional na discrepância em relação à referência, isso porque a região de ravina favoreceu a diminuição da nuvem densa de pontos na área de interesse, resultando em respostas aleatórias do produto final do RPA. As discrepâncias foram altas para o cálculo do volume negativo, variando de $39,6 \%$ a $85,2 \%$. Também se obteve valores de discrepâncias altas no comparativo de área de superfície, com valores que variaram de $60,3 \%$ a 95,6\%, não sendo assim recomendado o uso do RPA nas situações semelhantes aos testes aplicados.

No levantamento com o RPA na região de estudo 2, MORRO 2, onde existe uma ravina de maior abertura e menor oclusão, a mudança de sobreposição (70\%, 80\% e 90\%) não ocasionou uma mudança sistemática na discrepância em relação à referência, pois, como citado anteriormente, a região de ravina dificultou a formação da nuvem densa de pontos na área de interesse, resultando num aumento dos pontos espúrios no produto final do RPA. As discrepâncias foram altas no cálculo do volume negativo, variando de $24,9 \%$ a $57,7 \%$, restringindo muito o uso do RPA nas situações semelhantes.

O desvio padrão e variância do comparativo de dados de altimetria entre estação total e RPA foram baixos, significando que o uso do RPA como plataforma de obtenção de dados possui confiabilidade se utilizado em conformidade com boas práticas, e acarreta grande contribuição, visto que fornece bons resultados em regiões sem oclusão. As discrepâncias altas na análise dos volumes negativos de ravinas têm como motivo a baixa densidade de pontos. Como foi possível observar na análise da diferença de intensidade de pixel das representações matriciais de declividade, as regiões mais problemáticas são aquelas de maior oclusão e, consequentemente, menor densidade de pontos. 
De fato, a delimitação de processos erosivos através do uso do RPA tornaria mais rápido o processo de avaliação de ocorrência, principalmente quando da existência de cenários complexos. Recomenda-se a continuação de estudos associando a fotogrametria terrestre com a aerofotogrametria para compensar a oclusão, aumentando a densidade de pontos em regiões problemáticas. A definição de técnicas de RPA e fotogrametria terrestre sólidas seria de grande contribuição científica e viabilizaria a aplicação em projetos diversos. A verificação da aplicabilidade do sensoriamento remoto por imagens à baixa altura de voo se tornaria viável economicamente, visto que os valores atuais para a compra e operação de serviços com RPAS para sensoriamento remoto demonstram viabilidade econômica para aplicação.

\section{REFERÊNCIAS}

ALIXANDRINI JUNIOR, M. J.; SILVA, S. D. R. S. E.; FERNANDES, V. de O; CUNHA, A. A. Levantamento de patrimônio arquitetônico com RPA: estudo de caso do conjunto Santuário São Lazaro e São Roque e Casarão Lazareto, Salvador/BA. In: CONGRESSO LUSO BRASILEIRO PARA O PLANEJAMENTO URBANO, REGIONAL, INTEGRADO E SUSTENTÁVEL - PLURIS, 7., 2016, Maceió. Anais [...]. Maceió: Viva Editora, 2016. V.7, p. 1068-1079. Tema: Contrastes, Contradições Complexidades: Desafios Urbanos no Século XXI.

BERTONI, J.; LOMBARDI NETO, F. Conservação do solo. São Paulo: Ícone, 1990.

DIGITAL GLOBE. Information Products. Advanced elevation series. London: Digital Globe, 2013. Disponível em:

http://www.digitalglobe.com/sites/default/files/Advanced\%20Elevation\%20Series\%20 Datasheet.pdf. Acesso em: 24 jul. 2017.

GALVÃO, G. M.; ROSALEN, D. L. Acurácia da mosaicagem gerada por veículo aéreo não tripulado utilizado na agricultura de precisão. In: CONGRESSO BRASILEIRO DE ENGENHARIA AGRÍCOLA, 42., 2013, Fortaleza, CE. Anais [...]. Fortaleza, CE: CONBEA, 2013. p. 3-17. Tema: Os desafios para o desenvolvimento sustentável.

LIMA, V. C.; LIMA, M. R. O solo no meio ambiente: abordagem para professores do ensino. Curitiba: UFPR, 2007.

MIKHAIL, E. M.; BETHEL, J. S.; MCGLONE, J. C. Introduction to modern photogrammetry. NY: John Wiley, 2001.

SANTOS, A. G.; SEGANTINE, P. C. L. Avaliação da qualidade das coordenadas geográficas de mapas digitais. In: CONGRESSO BRASILEIRO DE CADASTRO TÉCNICO

MULTIFINALITÁRIO, 2006, Florianópolis, SC. Anais [...]. Florianópolis: Editora UFSC, 2006, p. 1-6.

SCHENK, T. Automatic generation of DEM's. In: MANUAL of photogrammetry addendum. New York, NY: American Society for Photogrammetry and Remote Sensing, 1996. p. 216 224.

SILVA, A. M. Curso de processamento digital de imagens. In: CONGRESSO

BRASILEIRO DE CARTOGRAFIA, 20, Porto Alegre, RS, 2000. Apostila.

Recebido: abril de 2019. Aceito: setembro de 2019. 